\title{
Article
}

\section{Antioxidant activity of Opuntia sp. fruit extracts on human sperm quality and cryopreservation cycle}

\author{
Martina Contino ${ }^{1}$, Elena Maria Scalisi ${ }^{1}$, Roberta Pecoraro ${ }^{1}$, Chiara Failla ${ }^{1}$, Sara Ignoto ${ }^{1}$, Lucia Buonfrate ${ }^{1}$, Antonio \\ Salvaggio' ${ }^{2}$, Pietro Calderaro ${ }^{3}$, Claudia Genovese ${ }^{3}$, Salvatore Antonino Raccuia ${ }^{3}$, Paola Asero ${ }^{4}$, Giovanna Caruso ${ }^{5}$, \\ Giovanni Brachitta ${ }^{5}$ and Maria Violetta Brundo ${ }^{1, *}$.
}

1 Department of Biological, Geological and Environmental Sciences, University of Catania, Catania, Italy; martina.contino@phd.unict.it; elena.scalisi@phd.unict.it; roberta.pecoraro@unict.it; chiarafailla95@gmail.com; sara.ignoto@phd.unict.it; buonfrate.1@studium.unict.it; mariavioletta.brundo@unict.it;

2 Experimental Zooprophylactic Institute of Sicily “A. Mirri”, Palermo, Italy; antonio.salvaggio@izssicilia.it

3 National Research Council, Institute for Agricultural and Forest Systems in the Mediterranean, Catania, Italy; pietro.calderaro@cnr.it; claudia.genovese@cnr.it; salvatoreantonino.raccuia@cnr.it

4 Centro Biomedico ASTER, Catania, Italy; paolaasero@hotmail.com

5 U.O. Fisiopatologia della Riproduzione Umana - Clinica del Mediterraneo, Ragusa, Italy; carusogio90@gmail.com; bracchitta@centroaster.com

* Correspondence: mariavioletta.brundo@unict.it ; Tel.: +390957306039.

\begin{abstract}
Opuntia sp. contain antioxidant phytochemicals resistant to ROS damage, whose excess negatively affect fertilization. We investigate the activity of fruit extracts of $O$. dillenii and $O$. ficus indica (cv red and yellow) on sperm quality and cryopreservation. In the first experiment, we exposed the samples to extracts $(50 \mu \mathrm{l})$ for 1 hour to then evaluate semen parameters (vitality, motility, acrosome reaction, DNA fragmentation and oxidative stress). The results showed a significant increase in the motility $(86 \% \pm 0.19$ for OFI cv yellow, $82 \% \pm 0.15$ for OFI cv red and $90 \% \pm 0.08$ for O. dillenii) compared to the control $(80 \% \pm 0.17)$. Moreover, we noted a reduction of DNA fragmentation on treated $(3 \% \pm 0.03$ in OFI cv yellow, $7 \% \pm 0.09$ in OFI cv red and $5 \% \pm 0.07$ in $O$. dillenii) than the control $(40 \% \pm 0.14)$. Furthermore, the oxidative stress was reduced after exposure to solutions $(3.15 \mathrm{mV}$ in the control and $2.94 \mathrm{mV}$ in the treated). In the second experiment, $50 \mu \mathrm{l}$ of solutions were added to the Freezing medium. After thawing, we observed an improvement in vitality and the number of intact acrosomes. Our results suggest that Opuntia sp. fruit extracts improve sperm quality, both before and after cryopreservation, optimizing the potential of fertilization of sperm cells.
\end{abstract}

Keywords: Antioxidants; Opuntia ficus indica; Opuntia dillenii; sperm quality; cryopreservation.

\section{Introduction}

In the last few years, natural phytochemicals of plants such as Opuntia ficus indica (L.) Mill. (OFI) and Opuntia dillenii Haw. (OD) have represented one of the research fields around which the scientific community developed a great interest for their protective effects on human health. It is known that the excess of highly unstable molecules like reactive oxygen species (ROS) and other free radicals is linked to the degradation of organic molecules (proteins, lipids, polysaccharides, DNA and RNA), stimulating, on the contrary, biochemical processes involved in the aetiology of diseases like cancer, diabetes, and ischemia [1,2].

Recently, some studies have associated a high level of ROS with a decrease in sperm quality, focusing the attention of researchers on the role of oxidative stress on infertility, a widespread problem globally. Nevertheless, spermatozoa tend to produce free radicals 
not only after stress conditions, for example during a freeze-thaw cycle, but also physiologically [3], since an adequate ROS concentration is essential for fertilization. The ROS contribution is fundamental for the capacitation, the acrosome reaction, the stability of mitochondrial sheath and motility [4,5]. In sperm cells, ROS are produced from nicotinamide-adenine dinucleotide phosphate (NADPH) in two ways. The first one concerns the NADPH-oxidase enzyme, present on the plasmatic membrane, that use the molecular oxygen $\left(\mathrm{O}_{2}\right)$ to produce superoxide anion $\left(\bullet \mathrm{O}_{2}^{-}\right)$, the substrate for hydrogen peroxide $\left(\mathrm{H}_{2} \mathrm{O}_{2}\right)$ synthesis [6]. This can promote the formation of hydroxyl radical $(\bullet \mathrm{OH})$, the most harmful product. The second way starts with NADPH-dehydrogenase, known as diaphorase, an enzyme located in the midpiece of spermatozoon [7] and responsible for the mitochondrial reaction at the base of ROS generation [8,9]. In a pathophysiology context, some studies have reported that men with teratozoospermia generate elevated ROS levels that impair the cell components due to the low quantity of antioxidants present on spermatozoa cytoplasm [10] because most of it is lost during the spermiohistogenesis. Additionally, ROS concentration could exceed the physiological range due to mitochondrial dysfunctions, so enzymatic (superoxide dismutase, catalase) and nonenzymatic (glutathione, ubiquinol, vitamins, polyphenols) systems fail to counteract the redox potential [11]. Furthermore, spermatozoa are rich in polyunsaturated fatty acids (PUFA), which undergo lipid peroxidation with consequent overproduction of free radicals. This process induces loss of membrane integrity and early capacitation, making spermatozoa less suitable for fertilization [12,13]. In addition, oxidative damage is implicated in the caspase activation and the induction of apoptosis with phosphatidylserine externalization that explain the dropped number of live sperm cells on semen fluid [14,15]. Interestingly, it is estimated that $25 \%$ of men present a high level of ROS on sperm and that is negatively correlated with fertility [16]. Cryobiology of gametes and freeze-thaw cycles are also associated with the free radical release, probably due to the water flow that can negatively affect the membrane and the organelles of spermatozoon [17]. In addition, the mitochondrial membrane is vulnerable to cryopreservation because it determines a change in its fluidity, influencing homeostasis and ROS biosynthesis [18]. Therefore, antioxidants, endowed with the ability to counterbalance the effects of free radicals, could contribute to the prevention of infertility, supporting traditional medicine, like confirmed by WHO in 1999 [19].

O. dillenii and O. ficus indica (to which three varieties are known: red, yellow and white), commonly called prickly pears and belonging to the genus of Cactaceae, have fruit, composed of pulp, peel, and seeds, rich in fructose, glucose, pectin, but also in ascorbic acid, betalains, flavonoids and vitamins [20]. The detailed review of Kaur et al. (2012), reported the possible therapeutic effects of OFI, which seems to have an antiinflammatory, anti-ulcerative, antioxidant and anti-carcinogenic activity [21]. Other studies had confirmed the same properties for OD [22, 23, 24, 25]. The great antioxidant effect can be inferred from the copious content of flavonoids, betalains and vitamins on the fruit. Betalains, divided into betaxantine and betacyanins, are nitrogen-containing pigments with a chemical structure based on betalamic acid and stored in the vacuole of cells [26]. Betacyanins colour fruit red, while betaxantines in yellow [27]. They revealed the electron-donating capability (HOMO energy) at $\mathrm{pH}<5$, which defines their dissociation degree, stabilizing the radical molecules [28]. Flavonoids, phenolic compounds, are stable phenoxy radical intermediates (PO), thanks to their resonance and their phenolic hydroxyl groups that can donate a hydrogen atom or a free radical, becoming scavengers [29]. Moreover, they have an aromatic ring in which they delocalize the unpaired electron [30]. A further contribution to the antioxidant properties is given by vitamins E, C and $\mathrm{K}$, abundant in Opuntia sp. [31]. Likewise, betalains, flavonoids and vitamins are scavengers of free radicals $[32,33]$, so they give up their electron, generating stable and non-toxic intermediates that can be eliminated by the cell before the reaction with organic molecules [34].

It is reasonable to think that the use of these fruit determines the rebalancing of the redox system on sperm cells. The aim of our study is to expose human spermatozoa to 
fruit extracts of OFI cv red (F2) and yellow (F1) and OD to assess the potential antioxidant effect, capable to bring benefits to sperm cells and optimizing the gametic quality. Moreover, we evaluated the extract supplementation on a cryopreservation medium because we hypothesized that the sucking substances reduce the ice crystal formation, protecting sperm cells from deterioration during the thawing.

\section{Materials and Methods}

\subsection{Chemicals:}

Folin-Ciocalteau, sodium carbonate, 2,2-diphenyl-1-picrylhydrazyl (DPPH), 6hydroxy-2,5,7,8-tetramethylchroman-2-carboxylic acid (Trolox) were purchased from Sigma-Aldrich (St. Louis, MO, USA). The polyphenols standards were supplied by Extrasynthese (Genay, France). Water Type I reagent grade was produced using a MilliQ water purification system (Millipore, MA, USA). Methanol, acetonitrile, water, and formic acid of HPLC grade were purchased from Merck (Darmstadt, Germany).

\subsection{Extract preparation of Opuntia sp.:}

In this study, clones of OD and OFI were used. The fruits, collected in July - October 2019 in Sicily (Italy), were harvested from a germplasm collection of CNR-ISAFOM, the section of Catania (Italy), grown under the same environmental conditions and with the same applied agronomic practices. The two cultivars of OFI used in this study were characterized with fruits red (F2) and yellow (F1) colours. For each accession, five fruits at the same ripeness stage were randomly collected. Juices were prepared according to Serra et al. (2013) [35]. The fruits were washed under tap water, spikes were removed with a brush and peel take out from the fruit manually. The pulps (containing seeds) were grounded and passed through a strainer to remove seeds. The juices were preserved under frozen storage $\left(-80^{\circ} \mathrm{C}\right)$ until analysis. Each sample $(1 \mathrm{~g})$ was added to $10 \mathrm{ml}$ aqueous methanol $(70 \%)$, sonicated for $20 \mathrm{~min}$ and centrifuged at $5000 \mathrm{rpm}$ for $10 \mathrm{~min}$. The supernatants were filtered through syringe filters $(0.45 \mu \mathrm{m}$, nylon) before analysis.

\subsection{Total phenolic content:}

The Total Phenolic Content (TPC) was performed using the protocol of Dewanto et al. (2002) [36] with some modifications. Aliquots (125 $\mu \mathrm{l})$ of each extract were mixed with $625 \mu \mathrm{l}$ of Folin Ciocalteau, previously diluted with ultrapure water $(1: 5, \mathrm{v} / \mathrm{v})$. After $6 \mathrm{~min}$, $1.25 \mathrm{ml}$ of $7 \% \mathrm{Na} 2 \mathrm{CO} 3$ aqueous solution and $1 \mathrm{ml}$ of ultrapure water were added. The mixture was shaken and placed in the dark at room temperature for $1 \mathrm{~h}$. Afterwards, the total content of phenolic compounds was measured at $760 \mathrm{~nm}$ using the BioSpectrometer UV/Vis spectrophotometer (Eppendorf, Hamburg, Germany). Gallic acid standard solution $\left(25-200 \mathrm{mg} \mathrm{L}^{-1}\right)$ was used for the calibration curve $\left(\mathrm{R}^{2}=0.9987\right)$. All measurements were performed in triplicate. The results were expressed as $\mathrm{mg}$ of gallic acid equivalent $100 \mathrm{~g}^{-1}$ of juice (mg GAE $100 \mathrm{~g}^{-1}$ ).

\subsection{Antioxidant activity:}

The antioxidant activity was evaluated using the method proposed by BrandWilliams et al. (1995) [37], with some modifications, through the evaluation of the free radical-scavenging effect on the 1,1-diphenyl-2-picrylhydrazine (DPPH) radical. $100 \mu$ lof supernatant was mixed with $2 \mathrm{ml}$ of $0.1 \mathrm{mM} \mathrm{DPPH}$ in methanol (freshly prepared). After incubating at room temperature for $30 \mathrm{~min}$ in the dark, the absorbance of the mixture was measured at $517 \mathrm{~nm}$. Trolox was used as a reference (calibration range $10-200 \mu \mathrm{mol} \mathrm{L}^{-1} ; \mathrm{R}^{2}$ $=0.9992$ ). All samples were analyzed in triplicates and the results are expressed as $\mu \mathrm{mol}$ Trolox equivalent (TE) $\mathrm{g}^{-1}$ of juice.

\subsection{Identification and quantification of phenolic compounds by HPLC:}

The phenolic acids and flavonoids profiles in the Opuntia sp. pulp extracts were determined using a liquid chromatography system Dionex UltiMate 3000 (Thermo Fisher 
Scientific, Waltham, MA, USA), including quaternary pump with an integrated fourchannel degasser, thermostated column compartment, autosampler and a four wavelength UV-Vis detector, all managed by the Chromeleon software. Separation was performed on a column Dionex Acclaim 120, C18, $3 \mu \mathrm{m}(4.6 \times 150 \mathrm{~mm})$ (Thermo Fisher Scientific, Waltham, MA, USA) with a gradient program at a flow rate of $1 \mathrm{ml} \mathrm{min}-1$. The column temperature was maintained at $30^{\circ} \mathrm{C}$ and the injection volume was $20 \mu \mathrm{l}$. The mobile phases consisted of water and formic acid (95:5, v/v) (eluent A) and acetonitrile, water, and formic acid (80:15:5, v/v/v) (eluent B). The gradient started with 3\% B up to 19 min, to reach $13 \%$ at $30 \mathrm{~min}$, to keep $13 \%$ up to $38 \mathrm{~min}$ and then to reach $14 \%$ at $55,30 \%$ at $65 \mathrm{~min}$ and $35 \%$ at $68 \mathrm{~min}$, and then return to the initial conditions. Chromatograms were recorded simultaneously at 280, 320 and $360 \mathrm{~nm}$. Identification of individual phenolic acids and flavonoids was carried out using the retention times and UV spectra, comparison with commercial standards, and running the samples after the addition of pure standards. The quantification of phenolic compounds was performed using the external standard method. The calibration curves showed a good linear correlation with $\mathrm{R}^{2}>0.999$. Relative standard deviations (RSD\%) were $\geq 0.5 \%$, showing good stability and reproducibility of the analysis.

\subsection{Preparation of semen samples:}

Semen samples were collected at M.A.P. (Medically Assisted Procreation) centre, MEDI. SAN. "Clinica del Mediterraneo", Ragusa, and A.S.T.E.R. "Centro di Diagnosi e Cura della Sterilità", Catania, from normospermic patients with a concentration higher than $60 \mathrm{million} / \mathrm{ml}$ and motility higher than 50\%. The samples were produced after ipsation and then they were cryopreserved and transported to the Laboratory of Reproductive Biotechnology at the University of Catania. Furthermore, before the cryopreservation, we added $50 \mu \mathrm{l}$ of the filtered and diluted extracts on some samples and finally the Freezing Medium. During the transport, the samples were placed in $2 \mathrm{ml}$ vials in a container with liquid nitrogen at the temperature of $-196^{\circ} \mathrm{C}$. Once in the laboratory, we transferred the vials into a cryogenic container.

\subsection{Thawing of semen samples and exposure to extracts:}

The vials were removed from the liquid nitrogen for the thawing, following the standard procedure, described by WHO Laboratory Manual for the Examination and Processing of Human Semen (2010) [38]: ten minutes at room temperature and then ten minutes in a water bath in an incubator at $37^{\circ} \mathrm{C}$ with $\mathrm{CO} 2$ at $5 \%$. After thawing, the vials were slightly shaken, and the seminal liquid was aliquoted in different Eppendorf tubes, to which we added a washing medium (Gems) with a 1:1 ratio. The solutions were centrifugated at $2.000 \mathrm{rpm}$ for $10 \mathrm{~min}$. The supernatant was discarded, and the pellet was resuspended with the medium in the controls (CTRL) and with medium enriched with $10 \%$ of the three extracts $(50 \mu \mathrm{l}),(\mathrm{OFI} F 1$ and F2, and OD), previously diluted with 1:4 ratio, in the other samples. They were incubated at $37^{\circ} \mathrm{C}$ with an inclination of $45^{\circ}$ to facilitate the swim-up (ascent of the sperm) for 1 hour. Then we evaluated the different semen parameters.

\subsection{Semen analysis:}

\subsubsection{Motility:}

Motility is the fundamental activity that allows the spermatozoa to go up the female genital tract to reach the oocyte. We measured the motility, according to the procedure of WHO (2010) [38], dividing spermatozoa into three categories: progressive motility (PR), non-progressive motility (NP) and immotility (IM). The analysis was made by placing 10 $\mu \mathrm{l}$ of sample on a slide and observing under an optical microscope at x400 magnification. We counted 100 spermatozoa at least.

\subsubsection{Vitality:}


We investigated the vitality through Eosin $Y(0.5 \%)$ that dyed dead spermatozoa in pink due to the loss of membrane integrity, compared to live spermatozoa that maintain their original colouring. The procedure involves the positioning of $10 \mu \mathrm{l}$ of sample on a slide in which we added $10 \mu \mathrm{l}$ of the dye. Then, we placed a coverslip. Finally, the slides were observed under an optical microscope Leica DMLB at x400 magnification. At least 100 spermatozoa were counted.

\subsubsection{Acrosome Reaction:}

The acrosome reaction (AR) is the process that induces the release of lytic enzymes through which spermatozoa open a passage on the space between zona pellucida and the plasmatic membrane of the oocyte. The test implies the use of two dyes, Trypan Blue, and Giemsa (eosin and azurII). First, one drop of the sample $(10 \mu \mathrm{l})$ and one drop of Trypan blue $(10 \mu \mathrm{l})$, with a 1:1 ratio, were placed on a slide and were faintly crawled. After the air drying, the slides were dipped in a fixative solution $(\mathrm{HCl} 1 \mathrm{~N}$, formaldehyde at $37 \%$ and azocarminium) for 5 minutes. Then, we washed the sample with distilled water, and we immersed it in Giemsa, composed of the dye at 7,5\% dissolved in distilled water, and left in the incubator at $37^{\circ} \mathrm{C}$ for 2 hours. We proceeded with a wash in tap water and distilled water. Finally, the slides were mounted with Entellan (Bio-Optica) and they were observed under an optical microscope Leica DMLB at x400 magnification. This protocol distinguishes dead spermatozoa (blue) from live ones (pink), but it also allows to determine the state of the acrosome. The intact acrosome is dyed in violet, while the damaged or lost acrosome is in lavender. For this test, we counted at least 100 sperm cells.

\subsubsection{DNA fragmentation:}

To assess the fragmentation of DNA, we used the Halosperm (HT-HS10), a kit of Halotech. Following the manufacturer instruction, we melted the agar (100 $\mu \mathrm{l})$ stored in an Eppendorf tube, at $90-100{ }^{\circ} \mathrm{C}$, and then we aliquoted it in two different Eppendorf tubes, $50 \mu \mathrm{l}$ in each one. We added $25 \mu \mathrm{l}$ of sample in $50 \mu \mathrm{l}$ of agar. Then, we withdraw $25 \mu \mathrm{l}$ of this mix and placed it in a slide covered with a coverslip. After $5 \mathrm{~min}$ in the fridge at $4{ }^{\circ} \mathrm{C}$, the coverslip was removed, and the slide was incubated with denaturant solution (DAsolution) for $7 \mathrm{~min}$. The DA-solution was token off using the lysis solution (LS-solution) that acted for $25 \mathrm{~min}$. We proceeded with the dehydration through a series of increasing ethanol solutions $\left(70^{\circ}, 80^{\circ}, 100^{\circ}\right)$ for 2 minutes each, letting the slides air dry once finished. Finally, we coloured the slides with Eosin $Y$ for $5 \mathrm{~min}$ and with Methylene-Blue for $2 \mathrm{~min}$. Once dry, the slides were read under a bright-field optical microscope with a 1000x objective. The protocol distinguishes spermatozoa with non-fragmented DNA that have halos around the head and sperm cells with fragmented DNA, without halos.

\subsubsection{Oxidative stress:}

To evaluate oxidative stress, we used the MiOXSYS System. It is based on the measurement of the Oxidation Reduction Potential (sORP), an overall index of the electron passage to which a biological component is subjected. sORP is an integrated measure of all oxidants and reducing agents, evaluating the oxidative damage that spermatozoa are undergoing due to free radicals. The test is carried out by placing a small aliquot $(30 \mu \mathrm{l})$ of seminal fluid on a sensor previously inserted in the analyser that applies a low voltage current. The electron activity is measured in millivolts $(\mathrm{mV})$.

\subsection{Statistical analysis:}

Statistical analysis was carried out using the CoSTAT software program. Data were submitted to Barlett's test for the homogeneity of variance and then analyzed using the ANOVA test, followed by Tukey's. Means were statistically separated based on the Student-Newman-Keuls test. Significance was accepted at $\mathrm{p} \leq 0.05$ level and all data are presented as mean \pm standard deviation (SD) [39]. 


\section{Result}

4.1. Total phenolic content and antioxidant activity:

The total phenolic content and the antioxidant activity of Opuntia sp. juices are reported in Table 1.

Total phenolic content showed an average value of $110.28 \mathrm{mg}$ GAE $100 \mathrm{~g}^{-1}$ of juice, ranging from 76.89 of $\mathrm{F} 1$ to $150.77 \mathrm{mg} \mathrm{GAE} 100 \mathrm{~g}^{-1}$ of O. dillenii.

The antioxidant activity showed a similar trend of total phenolic content, with the mean value of $3.15 \mu \mathrm{mol} \mathrm{TE} \mathrm{g}^{-1}$ of juice, varying significantly $(\mathrm{p} \leq 0.05)$ between 1.00 in F1 and $6.64 \mu \mathrm{mol} \mathrm{TE} \mathrm{g}{ }^{-1}$ in OD. Even then, the OD showed considerably higher contents than OFI, and also, as reported by Abdel-Hameed et al. (2014), the antioxidant capacity of red O. ficus indica (F2) was higher than the yellow cultivar (F1) [40].

Table 1. Total phenolic content and antioxidant activity of Opuntia juices.

\begin{tabular}{ccc}
\hline Genotype & $\begin{array}{c}\text { Total phenolic content (mg } \\
\left.\text { GAE 100 } \mathbf{~ g}^{-1}\right)\end{array}$ & $\begin{array}{c}\text { Antioxidant activity ( } \boldsymbol{\mu m o l} \\
\left.\text { TE } \mathbf{~ g}^{-1}\right)\end{array}$ \\
\hline O. ficus indica F1 & $76.89 \pm 0.08^{\mathrm{c}}$ & $1.00 \pm 0.143^{\mathrm{c}}$ \\
O. ficus indica F2 & $103.19 \pm 0.13^{\mathrm{b}}$ & $1.80 \pm 0.022^{\mathrm{b}}$ \\
O. dillenii & $150.77 \pm 5.95^{\mathrm{a}}$ & $6.64 \pm 0.043^{\mathrm{a}}$ \\
\hline
\end{tabular}

Data represent mean \pm standard deviation of three replications for each sample.

Different letters within the same column indicate differences at $\mathrm{P} \leq 0.05$.

4.2. Determination of phenolic compounds by HPLC:

A total of five different phenolic acids and five flavonoids were identified. The qualitative and quantitative profile of identified compounds is shown in Table 2 and indicates that the OD genotype exhibits the highest content of total measured polyphenols (7.717 mg L-1), about twice compared to OFI genotypes (4.147 $\mathrm{mg} \mathrm{L}^{-1}$ in F1 and $4.420 \mathrm{mg} \mathrm{L}^{-}$ ${ }^{1}$ in F2). The analysis showed significant differences in the content of polyphenols between the tested genotypes, in agreement with Medina et al. (2007), who found that the chemical composition of OD and OFI fruits were clearly different [41].

The highest concentration of phenolic acids was determined in OD $\left(5.006 \mathrm{mg} \mathrm{L}^{-1}\right)$, followed by F2 (2.919 $\left.\mathrm{mg} \mathrm{L}^{-1}\right)$ and F1 (1.255 $\left.\mathrm{mg} \mathrm{L}^{-1}\right)$, while among the flavonoids the highest concentration was determined in OFI F1 $\left(2.892 \mathrm{mg} \mathrm{L}^{-1}\right)$ and OD $\left(2.711 \mathrm{mg} \mathrm{L}^{-1}\right)$, followed by F2 (1.501 $\left.\mathrm{mg} \mathrm{L}^{-1}\right)$. Among the polyphenols measured, gallic acid is the compound mostly present in OD and F2 $\left(2.419 \pm 0.071 \mathrm{mg} \mathrm{L}^{-1}\right.$ and $2.081 \pm 0.057 \mathrm{mg} \mathrm{L}^{-1}$, respectively), while rutin is the most present in F1 $\left(1.758 \pm 0.051 \mathrm{mg} \mathrm{L}^{-1}\right)$.

Kaempferol was found only in OD $\left(0.025 \pm 0.005 \mathrm{mg} \mathrm{L}^{-1}\right)$ and in traces, contrary to Kuti (2004), who found it in all the samples analyzed (green-skinned, purple-skinned and redskinned of Opuntia sp.) [42]. These differences may be due to cultivar and genetic factors, environment, stress and agrotechnical processes, as well as to growth conditions, harvesting time, degree of ripeness, fruit processing and determination methods [43].

Table 2. Phenolic compounds composition $\left(\mathrm{mg} \mathrm{L}^{-1}\right)$ of Opuntia juices analyzed by HPLC.

$\begin{array}{llll}\text { Compound } & \text { O.ficus indica F1 } & \text { O.ficus indica F2 } & \text { O. Dillenii }\end{array}$




\begin{tabular}{cccc}
\hline Phenolic acids & & & \\
gallic acid & $0.742 \pm 0.028 \mathrm{c}$ & $2.081 \pm 0.057 \mathrm{~b}$ & $2.419 \pm 0.071 \mathrm{a}$ \\
neochlorogenic acid & $0.048 \pm 0.005 \mathrm{c}$ & $0.203 \pm 0.013 \mathrm{~b}$ & $0.694 \pm 0.027 \mathrm{a}$ \\
chlorogenic acid & $0.262 \pm 0.045 \mathrm{~b}$ & $0.054 \pm 0.010 \mathrm{c}$ & $0.750 \pm 0.023 \mathrm{a}$ \\
caffeic acid & $0.035 \pm 0.007 \mathrm{c}$ & $0.068 \pm 0.006 \mathrm{~b}$ & $0.405 \pm 0.018 \mathrm{a}$ \\
ferulic acid & $0.216 \pm 0.014 \mathrm{c}$ & $0.513 \pm 0.032 \mathrm{~b}$ & $0.738 \pm 0.040 \mathrm{a}$ \\
Total phenolic acids & $\mathbf{1 . 2 5 5}$ & $\mathbf{2 . 9 1 9}$ & $\mathbf{5 . 0 0 6}$ \\
\hline Flavonoids & & & \\
catechin & & & \\
rutin & $0.811 \pm 0.020 \mathrm{~b}$ & $0.536 \pm 0.012 \mathrm{c}$ & $1.353 \pm 0.066 \mathrm{a}$ \\
quercetin & $1.758 \pm 0.051 \mathrm{a}$ & $0.341 \pm 0.014 \mathrm{c}$ & $0.641 \pm 0.036 \mathrm{~b}$ \\
kaempferol & $0.323 \pm 0.022 \mathrm{c}$ & $0.624 \pm 0.016 \mathrm{~b}$ & $0.692 \pm 0.014 \mathrm{a}$ \\
isorhamnetin & $\mathrm{nd}$ & $\mathrm{nd}$ & $0.025 \pm 0.005 \mathrm{a}$ \\
Total Flavonoids & $0.152 \pm 0.009 \mathrm{~b}$ & $\mathrm{nd}$ & $0.313 \pm 0.042 \mathrm{a}$ \\
& $\mathbf{2 . 8 9 2}$ & $\mathbf{1 . 5 0 1}$ & $\mathbf{2 . 7 1 1}$ \\
\hline Total phenolic compounds & $\mathbf{4 . 1 4 7}$ & $\mathbf{4 . 4 2 0}$ & $\mathbf{7 . 7 1 7}$ \\
\hline
\end{tabular}

Data represent mean \pm standard deviation of three replications for each sample. Different letters within the same row indicate differences at $\mathrm{p} \leq 0.05$.

nd: not detected.

\subsection{Semen parameters of examples exposed to fruit extract after thawing:}

After $1 \mathrm{~h}$ of exposure, we observed lower motility on the control group $(80 \% \pm 0.17)$ compared to the treated, in which it corresponds to $86 \% \pm 0.19$ for OFI F1, $82 \% \pm 0.15$ for OFI F2 and $90 \% \pm 0.08$ for OD. The results are statistically significant with $\mathrm{p}<0.05$. The best result was obtained with OD.

The analysis of vitality, through the Eosin test, highlighted a high number of dead spermatozoa on the controls in which the viability was $78 \% \pm 0.19$, while it was $86 \% \pm 0.22$, $76 \% \pm 0.41$ and $85 \% \pm 0.22$, respectively on samples exposed to OFI cv yellow, OFI cv red and OD (Figure 1). The viability of the control was comparable with that of OFI cv red, while better results were obtained in the samples exposed to OD and OFI cv yellow.

The Trypan-blue test showed the acrosome that appeared damaged on the control compared to the samples enriched with the three extracts. The percentage of intact acrosome is equal to $19 \% \pm 0.14$ in the controls while, between the treated, the best appeared the OFI cv red $(31 \% \pm 0.20)$, followed by OFI $\mathrm{cv}$ yellow $(26 \% \pm 0.26)$ and $O D$ $(17 \% \pm 0.16)$ (Figure 2).

The Halosperm test highlighted an elevated number of sperm cells with nonfragmented DNA, and therefore with large halos, in the samples enriched with OFI F1 and OD, slightly less in the samples exposed to OFI F2, and a certain number of fragmented DNA, free of halos, in spermatozoa of the controls $(\mathrm{p}<0.05)$ (Figure 3). Indeed, the DNA fragmentation was evident in the control $(40 \% \pm 0.14)$, while it is almost absent in the exposed: $3 \% \pm 0.03$ in OFI cv yellow, $7 \% \pm 0.09$ in OFI $\mathrm{cv}$ red and $5 \% \pm 0.07$ in OD.

Oxidative stress was examined with the MiOXIS System through which we obtained the following result. The control groups showed a higher current passage $(3.15 \mathrm{mV})$ than the exposed $(2.94 \mathrm{mV})$. Therefore, the evidence indicates how the extracts reduce the oxidant amount, compared to the control groups.

\subsection{Semen parameters of samples exposed to extracts before cryopreservation:}

The addition of the extracts in the Freezing medium caused an improvement in motility after thawing, as this parameter was found higher in the exposed samples compared to the control. The percentage of motility corresponds to $70 \%$ in the control, a much lower value than of the treated: $98 \% \pm 0.2$ for OFI cv yellow, $97 \% \pm 0.15$ for OFI cv red and $95 \% \pm 0.19$ for OD. 
After thawing, viability appeared exceptionally high in the treated samples in which a high number of intact spermatozoa was found, suggesting that antioxidants, contained in the extracts, may protect the sperm cells from oxidative damage due to the change in membrane fluidity during cryopreservation and to the production of ROS. Indeed, the control had $37 \% \pm 0.22$ of live spermatozoa, while among the treated, the samples exposed to OD had $80 \% \pm 0.18$ of viable spermatozoa, followed by OFI cv red with $76 \% \pm 0.20$ and OFI cv yellow with $69 \% \pm 0.22$ (Figure 4 ).

The use of extract led to an improvement in the condition of the acrosome. It appeared more damaged in the control, in which only $16 \% \pm 0.24$ of spermatozoa was characterized by an intact acrosome. However, in the treated there was a very high percentage of normal and unaltered acrosomes $(50 \% \pm 0.19$ in OFI cv red, $55 \% \pm 0.25$ in OFI cv yellow and $70 \% \pm 0.15$ in OD) (Figure 5).

The exposure of spermatozoa to Opuntia sp. extracts protected sperm cells from DNA breaks, as our results highlight. The control showed a higher number of spermatozoa with fragmented chromatin $(30 \% \pm 0.16)$, compared to the treated ones $(10 \% \pm 0.18$ in OFI cV red, $9 \% \pm 0.16$ in OFI cv yellow and $3 \% \pm 0.14$ in OD) (Figure 6). From the results obtained through the MiOXIS, it was evident a greater passage of current in the control $(3.20 \mathrm{mV})$ compared to the treated $(2.50 \mathrm{mV})$, in which the values are superimposable.

\section{Discussion}

Phytochemicals are known for their protection of human health, especially for their antioxidant activity. Indeed, the excess of ROS is deleterious for the gametic quality and reproductive success when it is out of the physiological range. Furthermore, ROS level is an index of morphologic anomalies of spermatozoa and diseases like varicocele, metabolic syndrome, prostatitis, responsible for the poor sperm quality [44]. Our experiment provided a series of tests in which semen samples from normospermic donors were exposed to fruit extracts of $O$. ficus indica $\mathrm{cv}$ red (F2) and yellow (F1) and O. dillenii. In addition, we conducted another test, adding these extracts on cryopreservation medium to evaluate their output on the semen parameters after thawing

Then, we investigate the motility, vitality, acrosome reaction, fragmentation of DNA and oxidative stress. The evidence indicates how the extracts reduce the oxidant amount, compared to the control groups. Probably, antioxidant impacts are linked with the presence of betalains, flavonoids and vitamins, whose scavenger activity is due to chemical ring structures, capable of stabilizing scattered electrons, blocking the activation of a chain reaction and the passage of electrons [45]. Our experiment showed that the OD has a greater antioxidant power $\left(6.64 \pm 0.043^{\mathrm{a}} \mu \mathrm{mol} \mathrm{TE} \mathrm{g}^{-1}\right)$ than the other two fruit. This could be explained by the high quantity of flavonoids in this variety $\left(7.717 \mathrm{mg} \mathrm{L}^{-1}\right)$ compared to the others. All the OFI genotypes showed lower contents than OD genotype in agreement to Medina et al. (2007), who reported for two species of prickly pear from Tenerife Island, total phenolic contents equal to 117.0 and $45.2 \mathrm{mg} \mathrm{GAE} 100 \mathrm{~g}^{-1}$ for OD and OFI respectively [41]. The most abundant compound is gallic acid, found in OD compared to OFI, in which rutin is present in greater quantities. These results are in agreement with Abdel-Hameed et al. (2014), who analyzed the concentration of phenolic compounds in the juice of two cactus cultivars (Opuntia ficus indica Mill.) growing in Taif (KSA), although he found gallic acid and catechin more present in yellow cultivar, rutin more abundant in red cultivar, and quercetin in traces in all samples [40]. Also, Mata et al. (2016) identified caffeic acid, rutin, quercetin and isorhamnetin among the 32 compounds detected in the juice of OFI fruit growing in Portugal. Several studies have shown that consumption of Opuntia spp. fruits may present important health benefits due to the presence of bioactive compounds, and in particular of those bioavailable as quercetin, isorhamnetin and their derivates, studied in many matrices [46]. Moussa-Ayoub et al. (2016) illustrated the superiority of OD as one of the most important and promising fruit-producing cactus 
Opuntia sp., as the results showed that OD fruit's juice is rich in different antioxidant compounds such as vitamin C, phenolic compounds, and betacyanins [47].

In the controls, in which a drop of semen parameters was found, there was also an increase in the SORP. The results are reflected in other studies in which high levels of sORP were paralleled with the poor gametic quality (count, viability, morphology, motility) $[48,49,50]$. After the exposure to the extracts, we have shown a general improvement in all semen parameters, underlining how oxidative stress is correlated with a decrease in the gametic quality and therefore in the fertilization potential. We observed low motility in the control group compared to the treated. Our findings agree with those obtained by Benkhalifa et al. (2008) that highlighted an enhancement of sperm motility in samples exposed to betalains [51]. The reduction of sperm motility in the control is due to lipid peroxidation and alteration of proteins involved in the electron transport chain (ETC) in the mitochondrial membrane, resulting in the less production of ATP, essential for flagellum movements, suggesting that the speed of sperm depends on the turnover of mitochondrial membrane components [52,53]. Therefore, antioxidants could avoid slowing turnover, ensuring the proper functionality of mitochondria. From our result, it is possible to deduce a greater vitality in the treated than in the controls, due to greater resistance against oxidative damage. The most interesting value was obtained from the samples treated with OD and OFI cv yellow. The cascade, activated by ROS, explains the higher mortality in the control compared to treated, since lipid peroxidation causes the release from mitochondria of cytochrome $c$, involved in programmed cell death [54]. The acrosome functionality is also improved by the presence of antioxidants. Indeed, the Trypan-blue test showed the acrosome that appeared damaged on the control compared to the samples enriched with the three extracts. ROS production plays a crucial role during capacitation. ROS, in fact, ensure the activation of an enzymatic cascade that ends with the phosphorylation of the residues of proteins involved in the acrosome reaction $[55,56]$. The study conducted by Griveau et al. (1994) has shown that the addition of catalase enzyme in semen fluid causes a $47 \%$ decrease in the number of spermatozoa that release lysis enzymes from acrosome [57]. However, free radical, produced in an unchecked manner, leads to an early reaction, causing a reduction in the fertilization rate. Concerning our findings, we decided to investigate a further aspect, the DNA fragmentation, through the Halosperm test that highlighted an elevated number of sperm cells with nonfragmented DNA in the samples exposed to extracts compared to the control, in which there is acrosome damage greater than $30 \%$ compared to the treated. Numerous studies in literature reported how the ROS increasing is correlated with DNA fragmentation [58] and how the latter is connected to reproductive failure even after in-vitro fertilization (IVF) and intracytoplasmic injection (ICSI) [59,60]. Indeed, DNA peroxidation can lead to chromatin cross-linking or double-stranded breaks [61,62], mainly associated with the formation of adducts such as 8-hydroxy-20-deoxyguanosine (8-OHdG) [63]. DNA anomalies put the embryo at death risk, promoting abortion. In this context, the antioxidant role becomes the epicentre of the balance of oxidants/antioxidants system to protect sperm cells from insults of free radicals [64].

The purpose of the second experiment is to demonstrate that the application of extracts to the Freezing medium can improve the parameters of semen after thawing. First, we investigate the motility, whose percentage is stackable in all samples treated (about $90 \%$ ). Vitality and acrosome reaction were investigated by the acrosome reaction test. In this case, we highlighted a high amount of live sperm cells and with normal acrosome spermatozoa in the samples exposed to the three extracts compared to the control group. Our study showed that the use of Opuntia sp. extracts cause a decrease in the damage resulting from the thawing of the samples. Although cryobiology is essential for the conservation of spermatozoa, which can be used later, it determines a $50 \%$ reduction in the spermatozoa integrity and this is problematic, especially for patients with abnormal parameters $[65,66,67]$. The fortified resistance of spermatozoa is due to the activity of antioxidants that oppose the lipid peroxidation, responsible for the integrity loss of the mitochondrial and the plasmatic membranes. Furthermore, it is known that adding ROS 
during thawing can also cause increased DNA fragmentation and reduced motility $[68,69,70,71]$. Our results are also supported by other studies, which show that the exposure to antioxidants, for example to Vitamin E, also present in the fruit of Opuntia sp., cause an increase in the motility and survival rate of spermatozoa after thawing $[72,73,74]$. Vitamin E and other antioxidants supplementation exert a stimulation on sperm motility and drop the concentration of Malondialdehyde (MDA) [75], a stable product of fatty acids oxidation and indirect index of intensity of this event into the cells [76].

These results can be attributed to gallic acid and rutin. The study conducted by Abarikwu et al. (2014) established that gallic acid leads to improvements in stereoidogenesis and spermatogenesis with a consequent increase in sperm quality [77]. However, some studies have pointed out that gallic acid can also have pro-oxidant effects, responsible for cell damage with a decrease of SOD [78]. The controversial role of gallic acid seems to be associated with its concentration, which if elevated, determines the oxidation of organic molecules [79]. Likewise, Rutin has an antioxidant power that allows not only to reduce the concentration of ROS but also to improve the physiological properties of spermatozoa. Xu et al. (2020), observed that exposure to rutin determines an increase in the integrity of the membrane and mitochondria that also improved the fertilization yield and blastocyst formation rate [80].

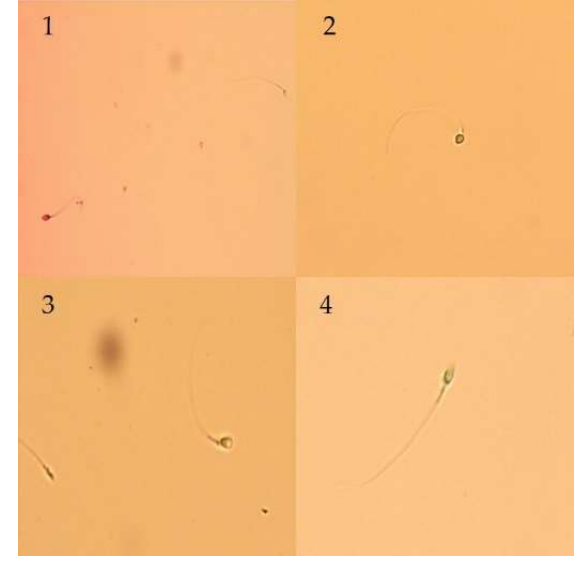

(a)

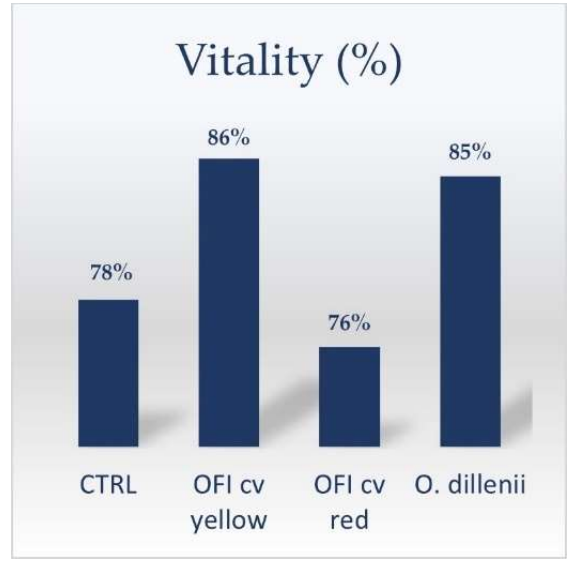

(b)

Figure 1. Vitality evaluation after exposure to extracts after thawing: a) Eosin test: 1) untreated sample (CTRL); 2) sample exposed to $O$. dillenii extracts; 3 ) sample treated with $O$. ficus indica $\mathrm{cv}$ red; 4) sample exposed to O. ficus indica $\mathrm{cv}$ yellow. b) percentage of the vitality of samples: CTRL; OFI cv yellow; OFI cv red and O. dillenii. 


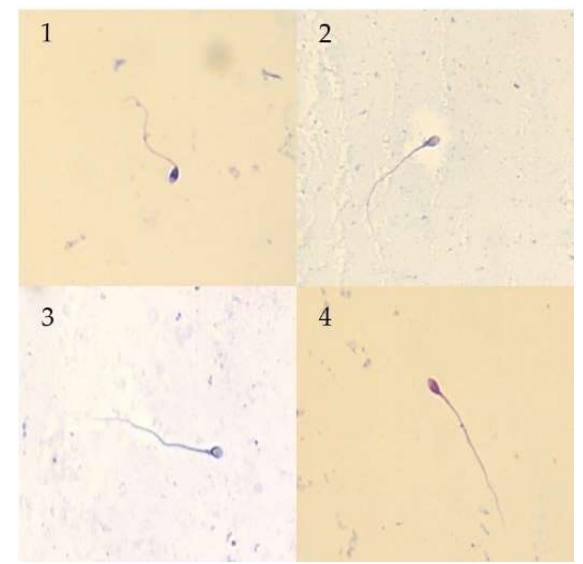

(a)

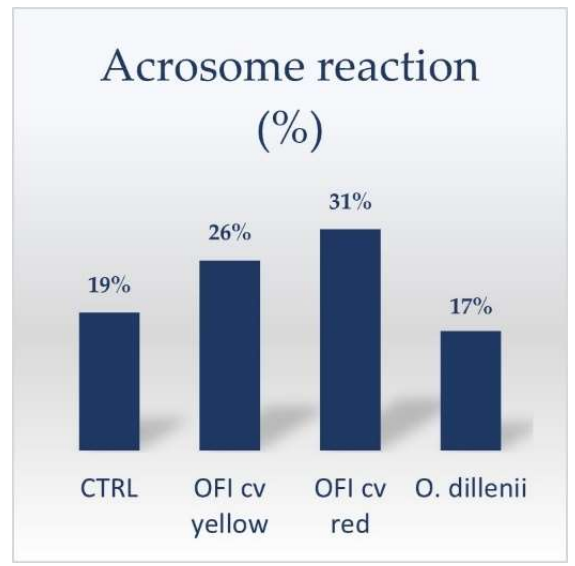

(b)

Figure 2. Acrosome reaction evaluation after exposure to extracts after thawing: a) Trypan Blue-Giemsa dye: 1) untreated sample (CTRL); 2) sample exposed to O. dillenii extracts; 3) sample treated with O. ficus indica cv red; 4) sample exposed to O. ficus indica cv yellow; b) the percentage of normal acrosome reaction: CTRL; OFI cv yellow; OFI cv red; O. dillenii.

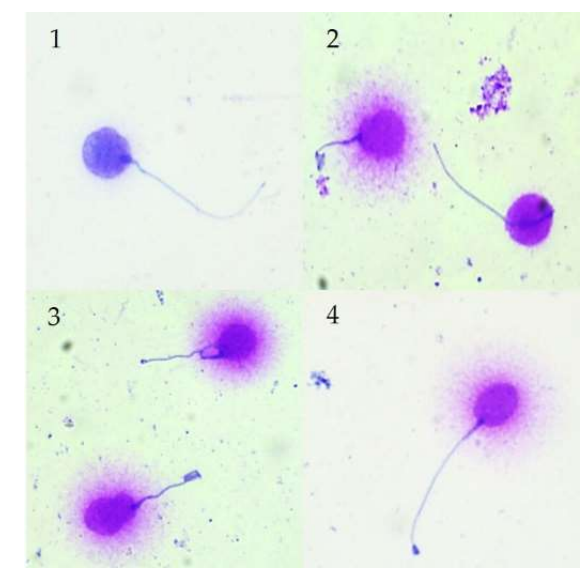

(a)

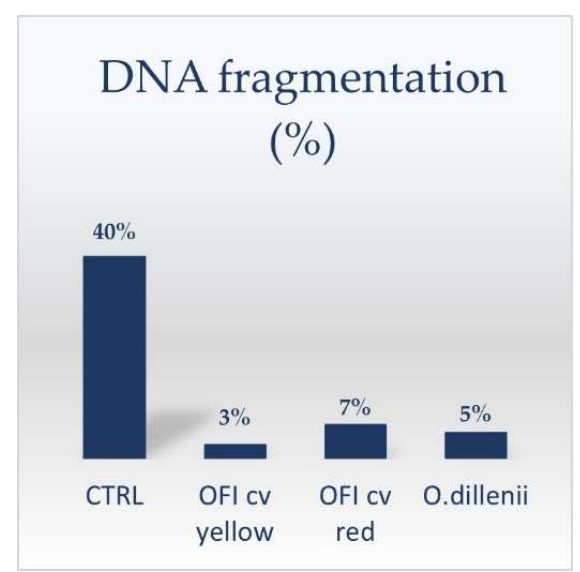

(b)

Figure 3. DNA fragmentation test after exposure to extracts after thawing: a) Halosperm test: 1) untreated sample (CTRL); 2) sample exposed to $O$. dillenii extracts; 3) sample treated with O. ficus indica $\mathrm{cv}$ red; 4) sample exposed to $O$. ficus indica cv yellow; b) percentage of fragmented DNA: CTRL; OFI cv yellow; OFI cv red; O. dillenii. 


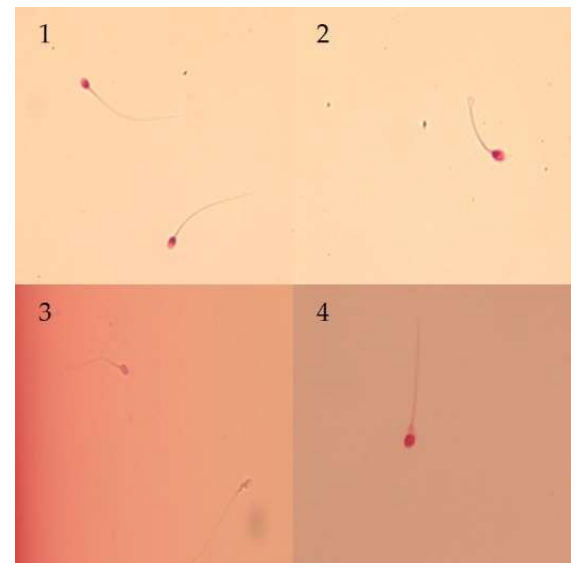

(a)

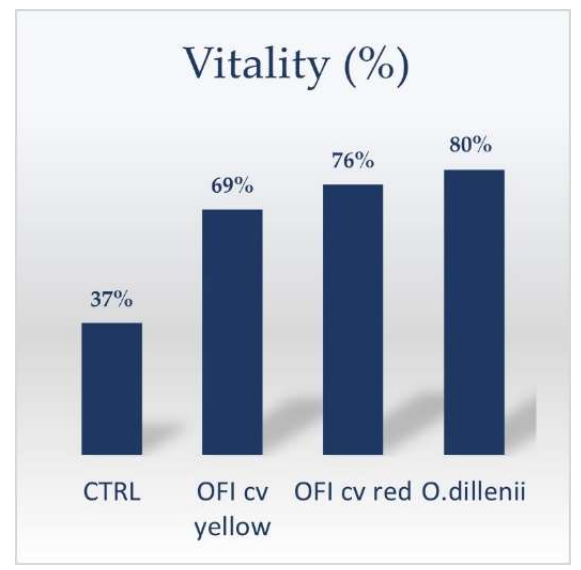

(b)

Figure 4. Vitality evaluation after exposure to extracts before cryopreservation: a) Eosin test: 1) untreated sample (CTRL); 2) sample exposed to $O$. dillenii extracts; 3 ) sample treated with O. ficus indica cv red; 4) sample exposed to O. ficus indica cv yellow. b) percentage of the vitality of samples: CTRL; OFI cv yellow; OFI cv red and O. dillenii.

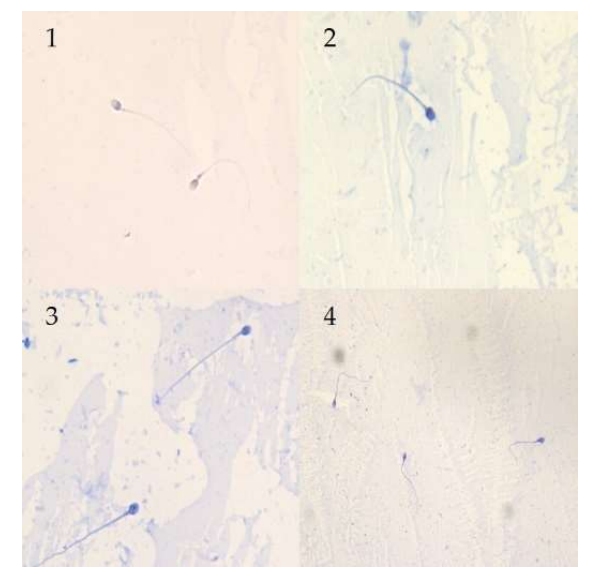

(a)

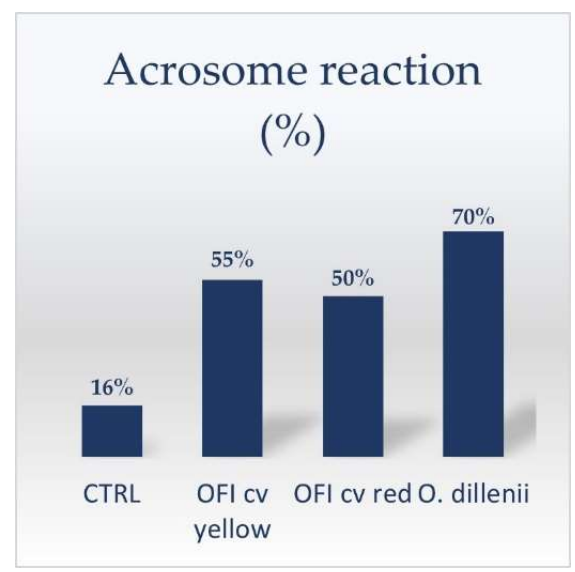

(b)

Figure 5. Acrosome reaction evaluation after exposure to extracts before cryopreservation: a) Trypan Blue-Giemsa dye: 1) untreated sample (CTRL); 2) sample exposed to O. dillenii extracts; 3) sample treated with O. ficus indica cv red; 4) sample exposed to $O$. ficus indica $\mathrm{cv}$ yellow; b) percentage of normal acrosome reaction: CTRL; OFI cv yellow; OFI cv red; O. dillenii. 


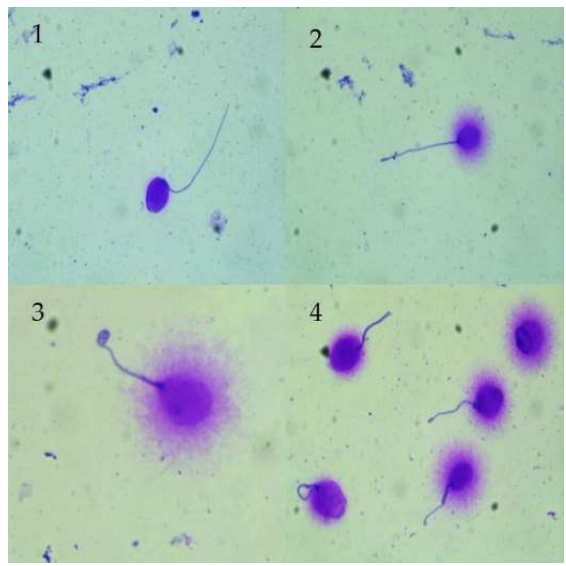

(a)

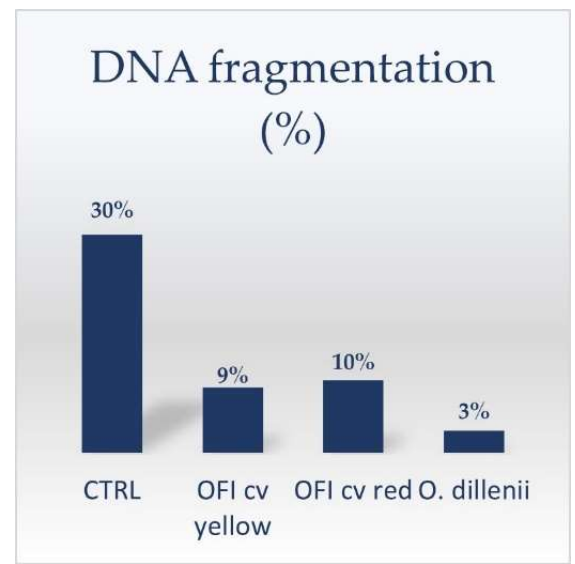

(b)

Figure 6. DNA fragmentation test after exposure to extracts before cryopreservation: a) Halosperm test: 1) untreated sample (CTRL); 2) sample exposed to O. dillenii extracts; 3) sample treated with O. ficus indica cv red; 4) sample exposed to O. ficus indica cv yellow; b) percentage of fragmented DNA: CTRL; OFI cv yellow; OFI cv red; O. dillenii.

\section{Conclusions}

In conclusion, our experimental evidence demonstrates how the antioxidants compounds of Opuntia sp. improve the gametic quality and reduce the damage induced by ROS . Therefore, oxidative stress could be considered a fundamental parameter of the semen and marker of sperm quality [81]. Indeed, in recent years, numerous studies have found a correlation between ROS overproduction and idiopathic infertility [82, 83]. Exposure to antioxidants has positive consequences on all parameters and improves the spermatozoa performance even after the freeze-thaw cycle. It is necessary the identification of substances for developing a medium that can optimize the sperm quality, namely of men with anomalies and reproductive difficulties.

\section{Conflict of interests}

The authors declare no conflict of interest.

\section{Funding}

This project was funding by University of Catania. Piano di incentivi per la ricerca di Ateneo (Pia.ce.ri.) and linea Open Access. Fondi di Ateneo 2020-2022.

\section{Acknowledgements}

R.P. thanks the PON project "AIM" funded by the European Social Found (ESF) CUP: E66C18001300007 for the financial support.

E.M.S thanks funds University of Catania, Italy, MIUR XXXIV cycle PhD. M.C. thanks funds University of Catania, Italy, MIUR XXXVI cycle PhD. S.I. thanks Industrial PhD programme (PON RICERCA ED INNOVAZIONE 2014-2020). 
1. Lenaz, G. Mitochondria and reactive oxygen species. Which role in physiology and pathology? Adv Exp Med Biol. 2012, 942, 93136.

2. Yoshihara, D; Fujiwara, N; Suzuki, K- Antioxidants: Benefits and risks for long-term health. Maturitas 2010, 67, 103-107.

3. Chatterjee, S.; Gagnon, C. Production of reactive oxygen species by spermatozoa undergoing cooling, freezing, and thawing. Mol Reprod Dev 2001, 59(4), 451-458.

4. Lamirande, E.D.; Gagnon, C. A positive role for the superoxide anion in triggering hyperactivation and capacitation of human spermatozoa. Int. J. Androl 1993, 16(1), 21-25.

5. Ichikawa, T.; Oeda, T.; Ohmori, H.; Schill, W.B. Reactive oxygen species influence the acrosome reaction but not acrosin activity in human spermatozoa. Int. J. Androl 1999, 22(1), 37-42.

6. Frederiks, W.M.; Vreeling-Sindelárová, H. Localization of glucose-6-phosphate dehydrogenase activity on ribosomes of granular endoplasmic reticulum, in peroxisomes and peripheral cytoplasm of rat liver parenchymal cells. Histochem. J. 2001, 33(6), 345-353.

7. Fraczek, M.; Kurpisz, M. The redox system in human semen and peroxidative damage of spermatozoa. Postepy Hig Med Dosw 2005, 59, 523-534.

8. Gavella, M.; Lipovac, V. NADH-dependent oxidoreductase (diaphorase) activity and isozyme pattern of sperm in infertile men. Arch. Androl. 1992, 28(2), 135-141.

9. Siegel. D.; Gibson., N.W.; Preusch, P.C.; Ross, D. Metabolism of diaziquone by NAD (P) H:(quinone acceptor) oxidoreductase (DT-diaphorase): role in diaziquone-induced DNA damage and cytotoxicity in human colon carcinoma cells. Cancer Res. 1990, 50(22), 7293-7300.

10. Dutta, S.; Henkel, R.; Sengupta, P.; Agarwal, A. Physiological Role of ROS in Sperm Function. In Male Infertility, $1^{\text {st }}$ ed; Parekattil, S., Esteves, S., Agarwal, A., Eds; Publisher: Springer, Cham, 2020, pp 337-345.

11. Castellini, C.; D’Andrea, S.; Cordeschi, G.; Totaro, M.; Parisi, A.; Di Emidio, G.; Tatone, C.; Francavilla, S.; Barbonetti, A. Pathophysiology of Mitochondrial Dysfunction in Human Spermatozoa: Focus on Energetic Metabolism, Oxidative Stress and Apoptosis. Antioxidants 2021, 10, 695.

12. Velando, A.; Torres, R.; Alonso-Alvarez, C. Avoiding bad genes: oxidatively damaged DNA in germ line and mate choice. Bioessays 2008, 30(11-12), 1212-1219.

13. Villegas, J.; Kehr, K.; Soto, L.; Henkel, R.; Miska, W.; Sanchez, R. Reactive oxygen species induce reversible capacitation in human spermatozoa. Andrologia 2003, 35(4), 227-232.

14. Henkel, R.; Schill, W.B. Sperm separation in patients with urogenital infections. Andrologia 1998, 30(S1), 91-97.

15. Schuppe, H.C.; Meinhardt, A.; Allam, J.P.; Bergmann, M.; Weidner, W.; Haidl, G. Chronic orchitis: a neglected cause of male infertility? Andrologia 2008, 40(2), 84-91.

16. Zini, A.; San Gabriel, M.; Baazeem, A. Antioxidants and sperm DNA damage: a clinical perspective. J. Assist. Reprod. Genet. 2009, 26(8), 427-432.

17. Alvarez, J.G.; Storey, B.T. Evidence for increased lipid peroxidative damage and loss of superoxide dismutase activity as a mode for sublethal cryodamage to human sperm during cryopreservation. J Androl 1992, 13, 232-241.

18. Said, T.M.; Gaglani, A.; Agarwal, A. Implication of apoptosis in sperm cryoinjury. Reprod Biomed Online 2010, 21(4), 456-462

19. World Health Organitation. Who monographs on selected medicinal plant, $1^{\text {st }}$ edi. Publisher: Geneva, Switzerland, 1999.

20. Andreu, L.; Nuncio-Jáuregui, N.; Carbonell-Barrachina, A.A.; Leguaa, P.; Hernández, F. Antioxidant properties and chemical characterization of Spanish Opuntia ficus-indica Mill. cladodes and fruits. J Sci Food Agric 2018, 98, 1566-157.

21. Kaur, M.; Kaur, A.; Sharma, R. Pharmacological actions of Opuntia ficus indica: A Review. J. App. Pharm. Sci 2012, 02(07), 1518.

22. Perfumi, M.; Tacconi, R. Antihyperglycemic effect of fresh Opuntia dillenii fruit from Tenerife (Canary Islands). Int. $j$ pharmacogn. 1996, 34(1), 41-47.

23. Galati, E.M.; Mondello, M.R.; Giuffrida, D.; Dugo, G.; Miceli, N.; Pergolizzi, S.; Taviano, M.F. Chemical characterization and biological effects of Sicilian Opuntia ficus indica (L.) Mill. fruit juice: antioxidant and antiulcerogenic activity. J. Agric. Food Chem. 2003, 51(17), 4903-4908.

24. Mishra, A. Preparation of Nutri Beverage Mix Using Opuntia dillenii (Cactus Fruit). J Biotechnol Biomater 2016, 6, 243.

25. Feugang, J.M.; Konarski, P.; Zou, D.; Stintzing, F.C.; Zou, C. Nutritional and medicinal use of Cactus pear (Opuntia spp.) cladodes and fruits. Front Biosci 2006, 11(1), 2574-2589.

26. Osorio-Esquivel, O.; Ortiz Moreno, A.; Álvarez, V.B.; Dorantes-Álvarez, L.; Giusti, M.M. Phenolics, betacyanins and antioxidant activity in Opuntia joconostle fruits. Food Res. Int. 2011, 44 (7), 2160-2168.

27. Albano, C.; Negro, C.; Tommasi, N.; Gerardi, C.; Mita, G.; Miceli, A.; De Bellis, L.; Blando, F. Betalains, Phenols and Antioxidant Capacity in Cactus Pear [Opuntia ficus-indica (L.) Mill. ]F ruits from Apulia(South Italy) Genotypes. Antioxidants 2015, 4, 269280.

28. Tutone, M.; Lauria, A.; Almerico, A.M. Theoretical Determination of the pK a Values of Betalamic Acid Related to the Free Radical Scavenger Capacity: Comparison Between Empirical and Quantum Chemical Methods. Interdiscip Sci 2016, 8, $177-185$.

29. Del Socorro Santos Díaz, M.; Barba de la Rosa, A.P.; Héliès-Toussaint, C.; Guéraud, F.; Nègre-Salvayre, A. Opuntia spp.: Characterization and Benefits in Chronic Diseases. Oxid Med Cell Longev 2017, 8634249.

30. Dai, J.; Mumper, R.J. Plant phenolics: extraction, analysis and their antioxidant and anticancer properties. Molecules. 2010, 15(10), 7313-7352. 
31. El-Mostafa, K.; El Kharrassi, Y.; Badreddine, A. Nopal cactus (Opuntia ficus-indica) as a source of bioactive compounds for nutrition, health and disease. Molecules 2014, 19 (9), 14879-14901.

32. Betancourt, C.; Cejudo-Bastante, M.J.; Heredia, F.J.; Hurtado, N. Pigment composition and antioxidant capacity of betacyanins and betaxanthins fractions of Opuntia dillenii (Ker Gawl) Haw cactus fruit. Food Res. Int. 2017, 101, $173-179$.

33. Gliszczyńska-Świgło, A.; Szymusiak, H.; Malinowska, P. Betanin, the main pigment of red beet: molecular origin of its exceptionally high free radical-scavenging activity. Food Addit Contam 2006, 23(11), 1079-1087.

34. Ramli, N.S.; Ismail, P.; Rahmat, A. Influence of Conventional and Ultrasonic-Assisted Extraction on Phenolic Contents, Betacyanin Contents, and Antioxidant Capacity of Red Dragon Fruit (Hylocereus polyrhizus). Sci 2014, $2014,964731$.

35. Serra, A.T.; Poejo, J.; Matias, A.A.; Bronze, M.R.; Duarte, C.M.M. Evaluation of Opuntia spp. derived products as antiproliferative agents in human colon cancer cell line (HT29). Food Res. Int. 2013, 54(1), 892-901.

36. Dewanto, V.; Wu, X.; Adom, K.K.; Liu, R.H. Thermal processing enhances the nutritional value of tomatoes by increasing total antioxidant activity. J. Agric. Food Chem. 2002, 50 (10), 3010-3014 .

37. Brand-Williams, W.; Cuvelier, M.E.; Berset, C. Use of a free radical method to evaluate antioxidant activity. LWT 1995, 28(1), 25-30.

38. World Health Organization. WHO Laboratory Manual for the Examination and Processing of Human Semen, $5^{\text {th }}$ ed; Publisher: Geneva, Switzerland, 2010.

39. Snedecor, G.W.; Cochran, W.G. Statistical Methods, 8th ed.; Ames, IA, Iowa State University Press, 1989.

40. Abdel-Hameed, E.S.S.; Nagaty, M.A.; Salman, M.S.; Bazaid, S.A. Phytochemicals, nutritionals and antioxidant properties of two prickly pear cactus cultivars (Opuntia ficus indica Mill.) growing in Taif, KSA. Food Chem. 2014, 160, 31-38.

41. Medina, E.M.D.; Rodríguez, E.M.R.; Romero, C.D. Chemical characterization of Opuntia dillenii and Opuntia ficus indica fruits. Food Chem. 2007, 103(1), 38-45.

42. Kuti, J.O. Antioxidant compounds from four Opuntia cactus pear fruit varieties. Food Chem. 2004, 85(4), 527-533.

43. Stintzing, F.C.; Herbach, K.M.; Mosshammer, M.R.; Carle, R.; Yi, W.; Sellappan, S.; Akoh, C.C. Color, betalain pattern, and antioxidant properties of cactus pear (Opuntia spp.) clones. J. Agric. Food Chem. 2005, 53(2), 442-451.

44. Barati, E.; Nikzad, H.; Karimian, M. Oxidative stress and male infertility: current knowledge of pathophysiology and role of antioxidant therapy in disease management. Cell. Mol. Life Sci. 2020, 77, 93-113.

45. Mata, A.; Ferreira, J.P.; Semedo, C.; Serra, T.; Duarte, C.M.M.; Bronze, M.R. Contribution to the characterization of Opuntia spp. juices by LC-DAD-ESI-MS/MS. Food Chem. 2016, 210, 558-565.

46. Moussa-Ayoub, T.E.; Jaeger, H.; Youssef, K.; Knorr, D.; El-Samahy, S.; Kroh, L.W.; Rohn, S. Technological characteristics and selected bioactive compounds of Opuntia dillenii cactus fruit juice following the impact of pulsed electric field pre-treatment. Food Chem. 2016, 210, 249-261.

47. Durackova, Z. Free radicals and antioxidants for non-experts. In: Systems Biology of Free Radicals and Antioxidants, 1 ${ }^{\text {st }}$ ed.; Publisher: Berlin, Germany, 2014; pp. 3-34.

48. Cavallini, G. Male idiopathic oligoasthenoteratozoospermia. Asian J Androl 2006, 8, 143-157.

49. Agarwal, A.; Ahmad, G.; Sharma, R. Reference values of reactive oxygen species in seminal ejaculates using chemiluminescence assay. J Assist Reprod Genet 2015, 32, 1721-1729.

50. Macanovic, B.; Vucetic, M.; Jankovic, A.; Stancic, A.; Buzadzic, B.; Garalejic, E. Correlation between sperm parameters and protein expression of antioxidative defense enzymes in seminal plasma: a pilot study. Dis Markers 2015, $2015,436236$.

51. Benkhalifa, M.; Cohen, M.; Tosti, E.; Cohen-Bacrie, P.; Ballashova, E.; Ménézo, Y. New Concept for Antioxidant Treatments for Sperm DNA Structure Alteration. International Congress of Andrology, ICA, Barcelona, Spain, 2008.

52. Koppers, A.J.; De Iuliis, G.N.; Finnie, J.M.; McLaughlin, E.A.; Aitken, R.J. Significance of mitochondrial reactive oxygen species in the generation of oxidative stress in spermatozoa. J. Clin. Endocrinol. Metab. 2008, 93, 3199-3207.

53. Zhu, Z.; Umehara, T.; Okazaki, T.; Goto, M.; Fujita, Y.; Hoque, S.A.M.; Kawai, T.; Zeng, W.; Shimada, M. Gene expression and protein synthesis in mitochondria enhance the duration of high-speed linear motility in boar sperm. Front. Physiol. 2019, 10, 252.

54. Amaral, A.; Lourenc, B.; Marques, M.; Ramalho-Santos, J. Mitochondria functionality and sperm quality. Reproduction 2013, 146, 163-174.

55. Vredenburgh-Wilberg, W.L.; Parrish, J.J. Intracellular pH of bovine sperm increases during capacitation. Mol Reprod Dev 1995, 40, 490-502.

56. Visconti, P.E.; Bailey, J.L.; Moore, G.D.; Pan, D.; Old-Clarke, P.; Kopf, G.S. Capacitation in mouse spermatozoa. I. Correlation between the capacitation state and protein tyrosine phosphorylation. Development 1995, 121, 1129-1137.

57. Griveau, J.E.; Renard, P.; Lannou, D.L. An in vitro promoting role for hydrogen peroxide in human sperm capacitation. Int. J. Androl. 1994, 17(6), 300-307.

58. Kao, S.H.; Chao, H.T.; Chen, H.W. Increase of oxidative stress in human sperm with lower motility. Fertil Steril 2008, 89, 11831190.

59. Sun, J.G.; Jurisicova, A.; Casper, R.F. Detection of deoxyribonucleic acid fragmentation in human sperm: correlation with fertilization in vitro. Biol. Reprod. 1997, 56, 602-607.

60. Lopes, S.; Jurisicova, A.; Sun, J.G.; Casper, R.F. Reactive oxygen specoes: potential cause for DNA fragmentation in human spermatozoa. Hum Reprod 1998, 13(4), 896-900.

61. Kodama, H.; Yamaguchi, R.; Fukuda, J.; Kasai, H.; Tanaka, T. Increased oxidative deoxyribonucleic acid damage in the spermatozoa of infertile male patients. Fertil Steril. 1997, 68, 519- 524. 
62. Twigg, J.P.; Irvine, D.S.; Aitken, R.J. Oxidative damage to DNA in human spermatozoa does not preclude pronucleus formation at intracytoplasmic sperm injection. Human Reprod. 1998, 13, 1864- 1871.

63. De Iuliis, G.N.; Thomson, L.K.; Mitchell, L.A.; Finnie, J.M.; Koppers, A.J.; Hedges, A.; Nixon, B.; Aitken, R.J. DNA damage in human spermatozoa is highly correlated with the efficiency of chromatin remodeling and the formation of 8-hydroxy-20deoxyguanosine, a marker of oxidative stress. Biol. Reprod 2009, 81, 517-524.

64. Menezo, Y.; Entezami, F.; Lichtblau, I. Oxidative stress and fertility: incorrect assumptions and ineffective solutions? Zygote 2012, 12, 1-11

65. Gao, D.Y.; Ashworth, E.; Watson, P.F. Hyperosmotic tolerance of human spermatozoa: separate effects of glycerol, sodium chloride, and sucrose on spermolysis. Biol. Reprod 1993, 49, 112-123.

66. McLaughlin, E.A. Cryopreservation and storage of sperm. In: Textbook of Assisted Reproductive Techniques: Laboratory and Clinical Perspectives, $5^{\text {th }}$ ed; Gardiner, D.K., Weissman, A., Howeles, C.M., Shoham, Z., Eds; Publisher: London, UK, 2001; Volume 1, pp. 261-272.

67. Woods, E.; Benson, J.; Agca, Y.; Critser, J. Fundamental cryobiology of reproductive cells and tissues. Cryobiology 2004, 48, 146156.

68. Aitken, R.J.; Krausz, C. Oxidative stress, DNA damage and the Y chromosome. Reproduction 2001, 122, $497-506$.

69. Gil-Guzman, E.; Ollero, M.; Lopez, M.C. Differential production of reactive oxygen species by subsets of human spermatozoa at different stages of maturation. Human Reprod. 2001, 16, 1922-1930.

70. Anzar, M.; He, L.; Buhr, M. Sperm apoptosis in fresh and cryopreserved bull semen detected by flow cytometry and its relationship with fertility. Biol. Reprod 2002, 66, 354-360.

71. Baumber, J.; Ball, B.A.; Linfor, J.J.; Meyers, S.A. Reactive oxygen species and cryopreservation promote DNA fragmentation in equine spermatozoa. J. Androl 2003, 24, 621-628.

72. Askari, H.A.; Check, J.H.; Peymer, N.; Bollendorf, A. Effect of natural antioxidants tocopherol and ascorbic acids in maintenance of sperm activity during freeze-thaw process. Arch. Androl 1994, 33, 11-15.

73. Pena, F.J.; Johannisson, A.; Wallgren, M.; Martinez, H.R. Antioxidant supplementation of boar spermatozoa from different fractions of the ejaculate improves cryopreservation: changes in sperm 188 membrane lipid architecture. Zygote 2004, 12, 117124.

74. Taylor, K.; Roberts, P.; Sanders, K.; Burton, P. Effect of antioxidant supplementation of cryopreservation medium on post-thaw integrity of human spermatozoa. Reprod Biomed online 2009, 18, 184-189.

75. Kessopoulou, E.; Powers, H.J.; Sharma, K.K.; Pearson, M.J.; Russell, J.M.; Cooke, I.D.; Barratt, C.L. A double-blind randomized placebo cross-over controlled trial using the antioxidant vitamin $\mathrm{E}$ to treat reactive oxygen species associated male infertility. Fertil. Steril. 1995, 64(4), 825-831.

76. Suleiman, S.A.; Ali, M.E.; Zaki, Z.M.S.; El-Malik, E.M.A.; Nasr, M.A. Lipid peroxidation and human sperm motility: protective role of vitamin E. J. Androl. 1996, 17(5), 530-537.

77. Abarikwu, S.O.; Oghenetega, F.A.; Durojaiye, M.A.; Alabi, A.F. Combined administration of curcumin and gallic acid inhibits gallic acid-induced suppression of steroidogenesis, sperm output, antioxidant defenses and inflammatory responsive genes. $J$ Steroid Biochem 2014, 143, 49-60.

78. Canbek, M.; Ustüner, M.C; Kabay, S.; Uysal, O.; Ozden, H.; Bayramo glu, G.; Sentürk, H.; Ozbayar, C.; Bayramoglu, A.; Ustüner, D.; Degirmenci, I. The effect ofgallic acid on kidney and liver after experimental renal ischemia/reperfusioninjury in the rats. AJPP 2011, 5, 1027-1033.

79. Lu, Z.; Nie, G.; Belton, P.S.; Tang, H.; Zhao, B. Structure-activity relationship analysis of antioxidant ability and neuroprotective effect of gallic acid derivatives. Neurochem. Int. 2006, 48, 263-274.

80. Xu, D.; Wu, L.; Yang, L. Rutin protects boar sperm from cryodamage via enhancing the antioxidative defense. Anim Sci J. 2020, 91, 13328.

81. Guerriero G.; Trocchia S.; Abdel-Gawad F.K.; Ciarcia G. Roles of Reactive Oxygen Species in the Spermatogenesis Regulation. Front. Endocrinol. 2014, 5, 56.

82. Jungwirth, A.; Diemer, T.; Dohle, G.R.; Giwercman, A.; Kopa, Z.; Tournaye, H.; Krausz, C. Guidelines on male infertility, European association of urology guidelines. Arnh. Neth. 2015, 1-41.

83. Amorini, A.M.; Listorti, I.; Bilotta, G.; Pallisco, R.; Saab, M.W.; Mangione, R.; Manca, B.; Lazzarino, G.; Tavazzi, B.; Lazzarino, G.; Bilotta, P. Antioxidant-Based Therapies in Male Infertility: Do We Have Sufficient Evidence Supporting Their Effectiveness?. Antioxidants 2021, 10, 220. 